\title{
UNBS5162 induces growth inhibition and apoptosis via inhibiting PI3K/AKT/mTOR pathway in triple negative breast cancer MDA-MB-231 cells
}

\author{
XIN YUE ${ }^{1}$, MINGZHONG LI ${ }^{2}$, DONGXIANG CHEN ${ }^{2}$, ZHENGHUA XU $^{2}$ and SHENGRONG SUN ${ }^{1}$ \\ ${ }^{1}$ Department of Breast and Thyroid Surgery, Renmin Hospital of Wuhan University, Wuhan, Hubei 430060; \\ ${ }^{2}$ Department of Surgical Oncology, The First People's Hospital of Jingzhou City, Jingzhou, Hubei 434000, P.R. China
}

Received September 14, 2017; Accepted August 22, 2018

DOI: $10.3892 /$ etm.2018.6675

\begin{abstract}
UNBS5162, a naphthalimide derivative, has a strong anticancer effect and low clinical hematological toxicity. UNBS5162 has been shown to have an anticancer effect in numerous cancer types, except triple negative breast cancer (TNBC). To explore this issue, TNBC MDA-MB-231 cells were selected, and the effect of UNBS5162 on their growth, proliferation and motility regulation was investigated in vitro. The results showed that UNBS5162 significantly inhibited the proliferation, migration and invasion of TNBC cells. In addition, the level of pro-apoptosis protein Bcl-2-associated $\mathrm{X}$ protein and active caspase- 3 increased, but apotptosis regulator BCL-2 decreased in MDA-MB-231 cells after UNBS5162 treatment, which demonstrated UNBS5162 treatment triggered cell apoptosis. Moreover, UNBS5162 reduced the phosphorylation levels of AKT serine/threonine kinase (AKT), mechanistic target of rapamycin kinase (mTOR), P70S6 kinase and eukaryotic translation initiation factor 4E-binding protein 1 in the phosphatidylinositol 3-kinase/AKT/mTOR (PAM) signaling pathway, which plays a critical role in cell proliferation, and apoptosis. Altogether, the results of the present study suggest that UNBS5162 effectively induces the growth inhibition and apoptosis of TNBC cells through regulation of the PAM pathway, which may be a candidate target for TNBC treatment.
\end{abstract}

\section{Introduction}

Breast cancer is the most common invasive cancer and the leading cause of cancer-related death among women worldwide $(1,2)$. Based on their patterns of gene expression $(3,4)$,

Correspondence to: Professor Shengrong Sun, Department of Breast and Thyroid Surgery, Renmin Hospital of Wuhan University, 99 Zhangzhidong Road, Wuhan, Hubei 430060, P.R. China E-mail: yuexin1980@yeah.net

Key words: PI3K, AKT, mTOR, proliferation, apoptosis, UNBS5162, triple negative breast cancer breast cancer can be classified into four major subtypes. Two of these are derived from estrogen receptor (ER)-positive tumours (luminal A and B), and two are derived from ER-negative tumours (basal-like and HER2 positive) (4-6). Triple negative breast cancer (TNBC) is a basal-like subtype of breast cancer that accounts for approximately $20 \%$ of all breast cancers $(7,8)$. Compared with other breast cancer subtypes, TNBC is a heterogeneous subgroup of tumours with a higher metastasis rate, worse prognosis, and higher relapse risk (8). Therefore, TNBC has attracted increasing amounts of attention in oncology research. At the St. Gallen International Breast Cancer Conference, it was confirmed that the major therapies for breast cancer include surgery, radiation therapy, endocrine therapy, targeted therapy and chemotherapy $(9,10)$. Surgery and radiotherapy are local therapy methods for the treatment of cancer. Because of the high metastasis and relapse rates of TNBC, other therapeutic approaches also need to be applied in TNBC treatment. However, TNBC cannot be treated by endocrine therapy because it lacks the expression of ER, progesterone receptor ( $\mathrm{PgR})$, and human epidermal growth factor receptor 2 (HER2) $(11,12)$. Although a number of possible targeted therapies have been studied, there are currently no ideal targeted agents for treating TNBC in the adjuvant, neoadjuvant, or metastatic setting (13). Standard chemotherapy, especially anthracycline-based agents, remains the backbone of current TNBC treatment strategies (8), but there is still a high risk for recurrence and disease progression $(14,15)$. Therefore, it is urgent to identify highly efficient and low-toxic treatment strategies for this specific subtype of breast cancer.

Naphthalimides, an important class of DNA intercalators, have shown high anti-cancer activity against a range of human cancer cell lines (16). One naphthalimide drug, amonafide, which is a DNA intercalator and a topoisomerase II poison (16), has good activity against advanced breast cancer $(17,18)$. Although amonafide has reached the phase 2 clinical trial stage, further application of amonafide is unlikely because of unexpected dose-limiting bone marrow toxicity (17-22). To minimize the toxicity, additional novel naphthalimide derivatives have been designed such as UNBS5162, which has anti-cancer effects without haematological toxicity $(23,24)$. Mijatovic et al $(23)$, reported that 
UNBS5162 displays significant anti-cancer activity in human prostate cancer orthotopic models, namely, PC-3 and DU-145. In vitro, UNBS5162 induces late apoptosis in DU-145 cells through inducing proautophagic effects or senescence, but not in PC-3 cells. In addition, UNBS5162 can induce a pRb-mediated growth delay, with cell arrest in the $\mathrm{G} 2$ phase of the cycle. Moreover, UNBS5162 has also been found to markedly decrease the expression of pro-angiogenic CXCL chemokines, which are potent autocrines and/or paracrine inducers of cancer cell growth $(25,26)$. In light of this, UNBS5162 may have multiple different effects that suppress the growth of cancer. UNBS5162 further more showed reliable anticancer properties and lower toxic side effects in Phase I clinical trials (24). Hence, UNBS5162 can be regarded as a promising anticancer drug. However, the effects and mechanism of UNBS5162 on TNBC are still unknown. We therefore performed a preliminary study to clarify this issue.

In the present study, we found UNBS5162 was effective in inducing growth inhibition and apoptosis of TNBC MDA-MB-231 cells. Moreover, we determined the effect of UNBS5162 on the PI3K/AKT/mTOR (PAM) pathway, because PAM represents the main signalling pathway responsible for cell metabolism, survival, proliferation and motility regulation (27) and is often activated in TNBC (28). We discovered that UNBS5162 could effectively suppress the growth of cells via inhibition of PAM pathway.

\section{Materials and methods}

Drugs andreagents. UNBS5162(N-\{2-[2-(dimethylamino)ethy 1]-1,3-dioxo-2,3-dihydro-1H-benzo[de]isoquinolin-5-yl\}urea) was purchased from MedChemExpress (Middlesex, NJ, USA). Paclitaxel was obtained from Sigma-Aldrich; Merck KGaA, (Darmstadt, Germany). RPMI-1640 medium was obtained from HyClone (Logan, Utah, USA). Fetal bovine serum (FBS), LDS Sample buffer and pre-stain protein marker were obtained from Thermo Fisher Scientific, Inc., (Waltham, MA, USA). Penicillin/streptomycin was purchased from Sigma-Aldrich; Merck KGaA. 0.25\% trypsin with EDTA and CCK8-kit were purchased from Beijing Solarbio Science \& Technology Co., Ltd., (Beijing, China). DMSO was purchased from Ameresco, Inc., (Framingham, MA, USA). RIPA Lysis Buffer, BCA Protein Assay kit, and Protease Inhibitor Cocktail were obtained from Beijing ComWin Biotech Co., Ltd., (Beijing, China). ECL developer was purchased from PTG (Chicago, IL, USA). Transwell was obtained from EMD Millipore (Billerica, MA, USA). Matrigel was purchased from BD Biosciences (Franklin Lakes, NJ, USA). Annexin V-FITC/PI Apoptosis Detection kit was purchased from 4A Biotech Co., Ltd., (Beijing, China). Primary antibodies against AKT (cat no. 9272), phosphorylated (p)-AKT (cat no. 13038), mTOR (cat no. 2972), p-mTOR (cat no. 2971), p-P70S6K (cat no. 9204) and P-4EBP1 (cat no. 9451) were purchased from Cell Signaling Technology, Inc., (Danvers, MA, USA). Anti-rabbit Immunoglobulin G (IgG) secondary antibodies (cat no. SA00001-2, HRP-conjugated goat anti-rabbit), anti-mouse Immunoglobulin $\mathrm{G}$ (IgG) secondary antibodies (cat no. SA00001-1, HRP-conjugated goat anti-mouse), primary antibodies against BCL-2 (cat no. 12789-1-AP), BAX (cat no. 60267-1-Ig), Caspase-3 (cat no. 19677-1-AP) and GAPDH (cat no. 10494-1-AP) were purchased from Proteintech Group, Inc., (Rosemont, IL, USA).

Cells culture. MDA-MB-231 cells and HFF-1 fibroblasts were purchased from Shanghai Institutes for Biological Sciences. Cells were incubated in RPMI 1640 containing 10\% serum, $100 \mathrm{U} / \mathrm{ml}$ penicillin, and $0.1 \mathrm{mg} / \mathrm{ml}$ streptomycin, and were maintained at $37^{\circ} \mathrm{C}$ in $5 \% \mathrm{CO}_{2}$. Cells were washed three times by PBS after the logarithmic growth phase and then were digested by trypsin. When the cells changed their morphology from a spindle shape to a circular shape, culture medium was added to the flask to inhibit the digestion. After centrifugation, the cells were resuspended in the culture medium and seeded in 6-well plates in preparation for subsequent experiments. In the meantime, UNBS5162 was diluted in 0.1\% DMSO. When grown to $80 \%$ confluency, $10 \mu \mathrm{M}$ UNBS5162 or $0.1 \%$ DMSO, respectively, was added to the cells as the experimental and negative control group (NC). Then, the cells were cultured for $24 \mathrm{~h}$.

Cell CCK-8 proliferation assay. MDA-MB-231 cells and HFF-1 fibroblasts were seeded in 96-well plates at a density of 1,000 cells/well in $100 \mu \mathrm{l}$ of culture medium and were allowed to attach overnight in a $\mathrm{CO}_{2}$ incubator. In the first group, MDA-MB-231 cells and HFF-1 fibroblasts were treated with UNBS5162 at concentrations of $0,0.1,1,10$, and $100 \mu \mathrm{M}$ for a period of $72 \mathrm{~h}$. In the second group, MDA-MB-231 cells were treated with $10 \mu \mathrm{M}$ UNBS5162, $10 \mu \mathrm{M}$ paclitaxel and $0.1 \%$ DMSO respectively for 24,48 , and $72 \mathrm{~h}$. The selection of drug concentration was referred to the previous literatures $(23,29)$. After the treatment, $10 \mu \mathrm{l}$ CCK-8 solution was added to each well of the plate. Cells were incubated for $1.5 \mathrm{~h}$ in the incubator at $37^{\circ} \mathrm{C}$. Then, the optical density of the cells was measured using a microplate reader at an absorbance of $450 \mathrm{~nm}$. Each sample was evaluated in triplicate.

Flow cytometric analysis of apoptosis with annexin V/PI double staining. After MDA-MB-231 cells were treated with $10 \mu \mathrm{m}$ UNBS5162 or $0.1 \%$ DMSO respectively for $24 \mathrm{~h}$, the cells were digested by trypsin without EDTA, centrifuged for 5 min, re-suspended in pre-cooled PBS at $4^{\circ} \mathrm{C}$, and centrifuged again. After centrifugation the supernatant was discarded. The cells were re-suspended in binding buffer solution. The density of cell suspension was $1-5 \times 10^{6}$ cells $/ \mathrm{ml}$. FITC-Annexin $\mathrm{V}(5 \mu \mathrm{l})$ and PI $(5 \mu \mathrm{l})$ were added to $100 \mu \mathrm{l}$ of cell suspension in a $5 \mathrm{ml}$ polystyrene tube. The mixture was incubated in the dark at room temperature for $15 \mathrm{~min}$, and then mixed with $400 \mu \mathrm{l}$ of binding buffer. Subsequently, the stained cells were analysed by flow cytometry using a FACScan flow cytometer. Each sample was evaluated in triplicate.

Cell migration and invasion assays. Cell migration and invasion assays were carried out in 24-well plates using transwell polycarbonate membrane filter inserts $(8 \mu \mathrm{m}$ pore size; BD Biosciences.

After MDA-MB-231 cells were incubated in culture medium with UNBS5162 or DMSO respectively for $24 \mathrm{~h}$, the cells were digested by trypsin, washed once with culture medium, centrifuged and re-suspended in serum-free medium. 
For the migration assay, the cells were suspended in serum-free medium $\left(100 \mu 1,1 \times 10^{5}\right.$ cells/well $)$ and placed directly in the upper chamber of a transwell.

For the invasion assay, matrigel was diluted in serum-free medium (100 $\mu \mathrm{l}$, at a ratio of 1:6), added to the upper chamber of a transwell, incubated in the incubator for $4 \mathrm{~h}$, and dried in serum-free medium. Then, cells suspended in serum-free medium $\left(100 \mu \mathrm{l}, 1 \times 10^{5}\right.$ cells/well $)$ were placed in the matrigel-coated upper chamber of a transwell.

The lower chamber contained medium with $10 \%$ FBS as a chemoattractant. Following incubation of the cells at $37^{\circ} \mathrm{C}$ in $5 \% \mathrm{CO}_{2}$ for $24 \mathrm{~h}$, the filters were removed. Non-migrating cells were wiped off the upper side of the filter with cotton swabs. Migratory cells on the lower side of the filter were fixed in $4 \%$ paraformaldehyde for $30 \mathrm{~min}$, stained with $0.1 \%$ crystal violet for $20 \mathrm{~min}$, and then rinsed in PBS. After the filters were subjected to microscopic inspection (magnification, $\mathrm{x} 200$ ), the number of the migratory cells was determined by counting five random microscopic fields per filter. Each sample was evaluated for three independent experiments.

Western blot analysis. After treatment with drugs for $24 \mathrm{~h}$, cells were washed with PBS twice and lysed in RIPA buffer containing protease inhibitors $(15 \mathrm{mM} \mathrm{NaCl}, 1 \mathrm{mM} \mathrm{MgCl}$, $1 \mathrm{mM} \mathrm{MnCl} 2,2 \mathrm{mM} \mathrm{CaCl}_{2}, 2 \mathrm{mM}$ phenylmethylsulfonyl fluoride, and protease inhibitor mixture) on ice for $30 \mathrm{~min}$. After centrifugation at $13,000 \mathrm{x}$ g for $20 \mathrm{~min}$ at $4^{\circ} \mathrm{C}$, the supernatant containing the protein lysates was collected. Then, the protein concentration was estimated using the BCA method. The protein lysates were heated at $95^{\circ} \mathrm{C}$ for $5 \mathrm{~min}$. Equal amounts of protein $(20 \mu \mathrm{g})$ were separated by SDS-PAGE and transferred onto a PVDF membrane. Membranes were blocked with $5 \%$ nonfat milk for $1 \mathrm{~h}$ and then incubated with the primary antibody overnight at $4{ }^{\circ} \mathrm{C}$ with antibodies against AKT (1:1,000 dilution), p-AKT (1:1,000 dilution), mTOR (1:1,000 dilution), p-mTOR (1:1,000 dilution), p-P70S6K (1:1,000 dilution), P-4EBP1 (1:1,000 dilution), BCL-2 (1:1,000 dilution), BAX (1:1,000 dilution), active caspase-3 (1:1,000 dilution), and GAPDH (1:5,000 dilution) separately. After being washed with TBST buffer three times for $15 \mathrm{~min}$, the membranes were incubated with the secondary antibody (diluted 1:5,000) for $1 \mathrm{~h}$ at room temperature. Membranes were washed again three times for 15 min with blocking solution and then photographed using the ECL detection system. Each sample was evaluated for five independent experiments. The intensity of signal on each membrane was analysed by using the Quantity One software. GAPDH was used as a loading control. Each membrane was normalized to GAPDH.

Statistical analysis. Each experimental value was expressed as the means \pm standard (SD) and analyzed using Student's t test or One-way ANOVA with Duncan's multiple comparison post hoc test. All analyses were performed with SPSS 18.0 software. $\mathrm{P}<0.05$ was considered to indicate a statistically significant difference.

\section{Results}

UNBS5162 inhibits the proliferation of MDA-MB-231 cells. To determine the effects of UNBS5162 on TNBC cells, the viability of MDA-MB-231 cells treated with UNBS5162 was analysed using CCK-8 assay. MDA-MB-231 cells and HFF-1 fibroblasts were treated with UNBS5162 at concentrations of $0,0.1,1,10$, and $100 \mu \mathrm{M}$ for a period of $72 \mathrm{~h}$. As shown in Fig. 1A, we found 1, 10, and $100 \mu \mathrm{M}$ UNBS5162 treatment could decrease the viability of MDA-MB-231 cells in a dose-dependent manner. Moreover, for fibroblasts treated with UNBS5162 at different doses, their viability was inhibited only in the $100 \mu \mathrm{M}$ UNBS5162 treated group (Fig. 1B). Therefore, in the following experiments, $10 \mu \mathrm{M}$ UNBS5162, a highly effective and low toxicity dose, was used (Fig. 1C). We also observed the time-dependent roles of UNBS5162 in MDA-MB-231 cells. Paclitaxel at $10 \mu \mathrm{M}$, a dose that shows anticancer roles in MDA-MB-231 cells, was selected as the positive control. Similar to paclitaxel, UNBS5162 significantly suppressed the proliferation of MDA-MB-231 cells at 48 and $72 \mathrm{~h}(\mathrm{P}<0.05)$. Thus, these results indicated that UNBS5162 suppressed the proliferation of MDA-MB-231 cells.

UNBS5162 induces apoptosis of MDA-MB-231 cells. Apoptosis of MDA-MB-231 cells was measured quantitatively by flow cytometry after staining with Annexin V-FITC and PI. As shown in Fig. 2, a quadrant diagram of flow cytometry shows the discrimination between live cells (annexin $\mathrm{V}$-FITC $/ \mathrm{PI}^{-}$, lower left quadrant), early apoptosis cells (annexin $\mathrm{V}$-FITC ${ }^{+} / \mathrm{PI}^{-}$, lower right quadrant), late apoptotic cells (annexin $\mathrm{V}-\mathrm{FITC}^{+} / \mathrm{PI}^{+}$, upper right quadrant) and necrotic cells (annexin $\mathrm{V}-\mathrm{FITC}^{-} / \mathrm{PI}^{+}$, upper left quadrant). Overall, $4.88 \pm 0.4 \%$ of the cells were undergoing apoptosis in the negative control group, which included $1.87 \%$ early apoptotic cells and $3.01 \%$ late apoptotic cells. Meanwhile, the proportion of apoptotic cells rose to $13.3 \pm 0.7 \%$ in the UNBS5162 treated group, which included $9.07 \%$ early apoptotic cells and $4.23 \%$ late apoptotic cells.

To further study the effects of UNBS5162 on cell apoptosis, western blot assays were also performed. The expression of BCL-2, an anti-apoptosis protein, was decreased (Fig. 3). Meanwhile, the expression levels of pro-apoptosis proteins BAX and active caspase-3 were increased remarkably (Fig. 3).

All these results indicated UNBS5162 could effectively induce the apoptosis of MDA-MB-231 cells.

UNBS5162 inhibits the migration and invasion of MDA-MB-231 cells. To address whether UNBS5162 affects cell invasion and migration, we subsequently conducted transwell assays as described in the Methods section. In these assays, the cells were pretreated with UNBS5162 and DMSO respectively for $24 \mathrm{~h}$. According to the results of CCK-8 proliferation assay, the viability of cells had no significant difference between UNBS5162 treated group and negative control group after treated with drugs for $24 \mathrm{~h}$. Besides, cells added into the chamber are the same between UNBS5162 treated group and negative control group. Therefore, during the early stages of the transwell assays, the viability and numbers of cells in the upper side of the membrane in these two groups are similar. These preconditions can confirm the effectiveness and accuracy of the experimental results.

In the invasion assay, compared to the NC group, the number of the invading cells in the UNBS5162 treated group was decreased significantly $(\mathrm{P}<0.05$; Fig. $4 \mathrm{~A}$ and $\mathrm{B})$. In the 

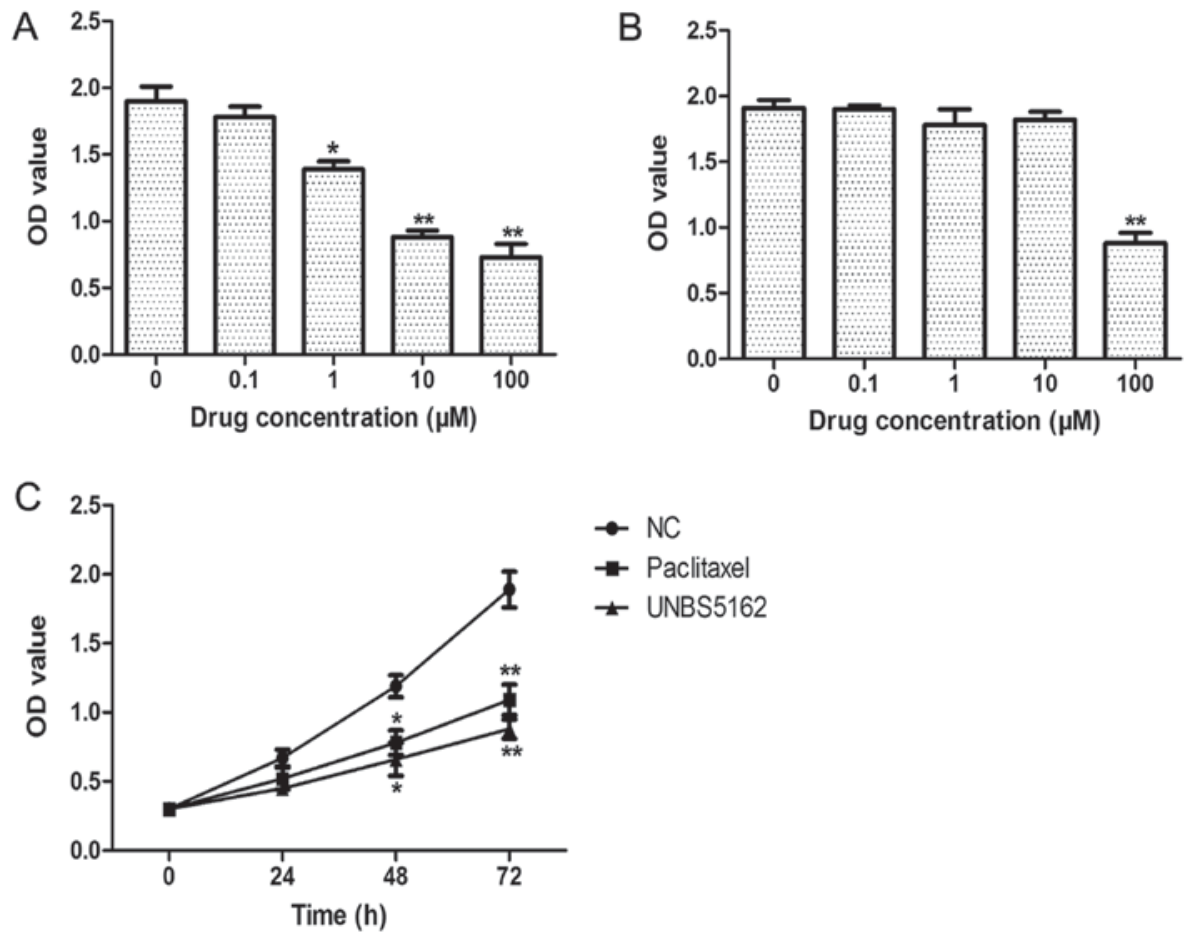

Figure 1. Effect of UNBS5162 on cells determined by CCK-8 assay. (A) Dose dependence of UNBS5162 on TNBC MDA-MB-231 cells after $72 \mathrm{~h}$ exposure. (B) Dose dependence of UNBS5162 on HFF-1 fibroblasts after $72 \mathrm{~h}$ exposure. (C) Time dependence of drugs on MDA-MB-231 cells. In these experiments, $10 \mu \mathrm{M}$ paclitaxel was used as the positive control group and 0.1\% DMSO was used as the negative control group (NC). Each experiment was assessed in triplicate. The data are presented as the mean $\pm \mathrm{SD}$. ${ }^{*} \mathrm{P}<0.05$ and ${ }^{* * *} \mathrm{P}<0.01$ vs. the negative control group. Comparison was made by one-way ANOVA followed by Duncan's multiple comparison post hoc test.

A

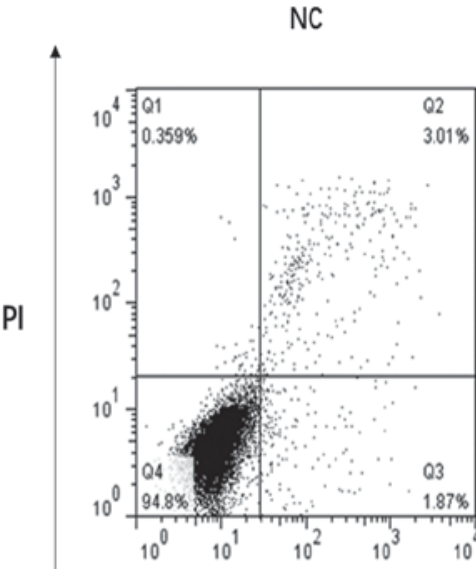

UNBS5162

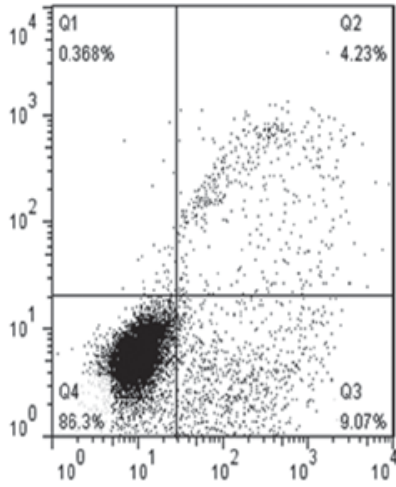

AnnexinV FITC

B

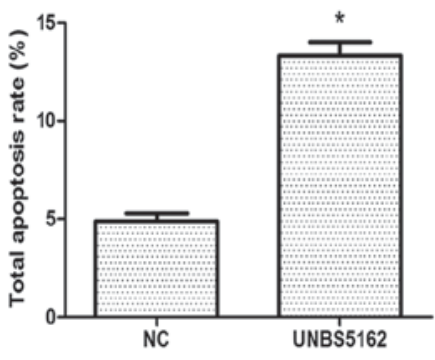

C

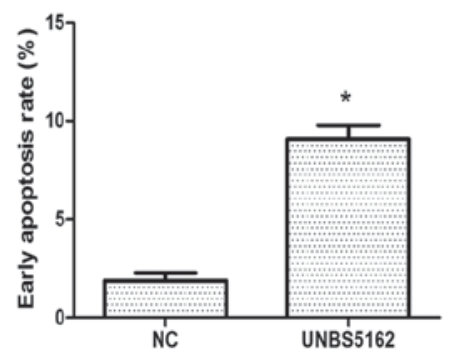

D

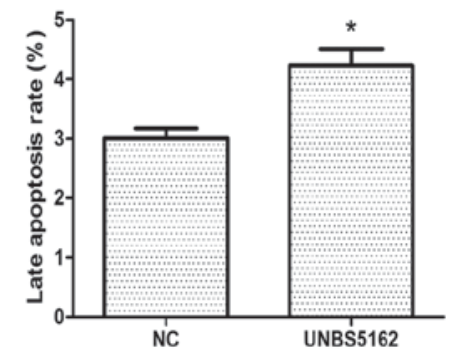

Figure 2. The effect of UNBS5162 on MDA-MB-231 cell apoptosis detected by flow cytometric analysis. (A) The two diagrams of flow cytometry are representative data from two independent experiments. MDA-MB-231 cells were treated with DMSO, as negative control group (NC). MDA-MB-231 cells were treated with UNBS5162, as experimental group. (B-D) Quantitative analysis of total (B), early (C) and late (D) apoptotic rate was performed. Each experiment was carried out in triplicate. The data are presented as the mean $\pm \mathrm{SD}$. ${ }^{*} \mathrm{P}<0.05$ vs. the negative control group. Comparison was made by Student's $\mathrm{t}$ test. 
A

BCL-2

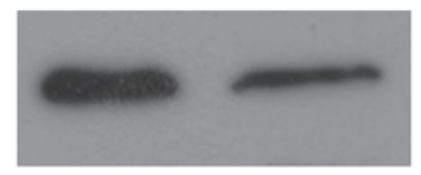

BAX
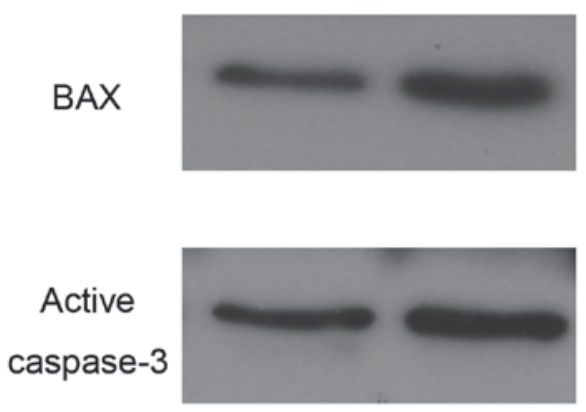

GAPDH

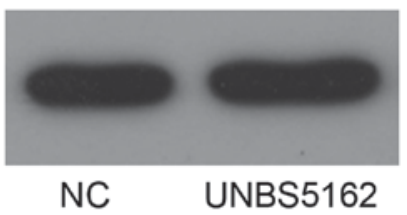

B

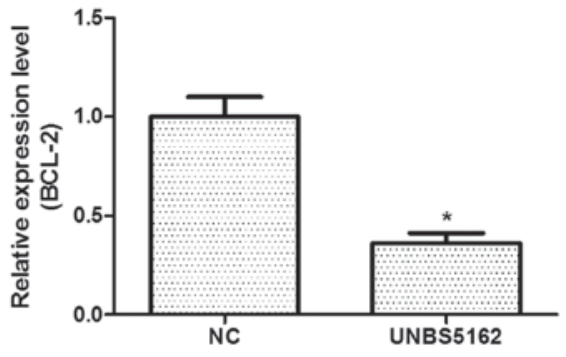

C
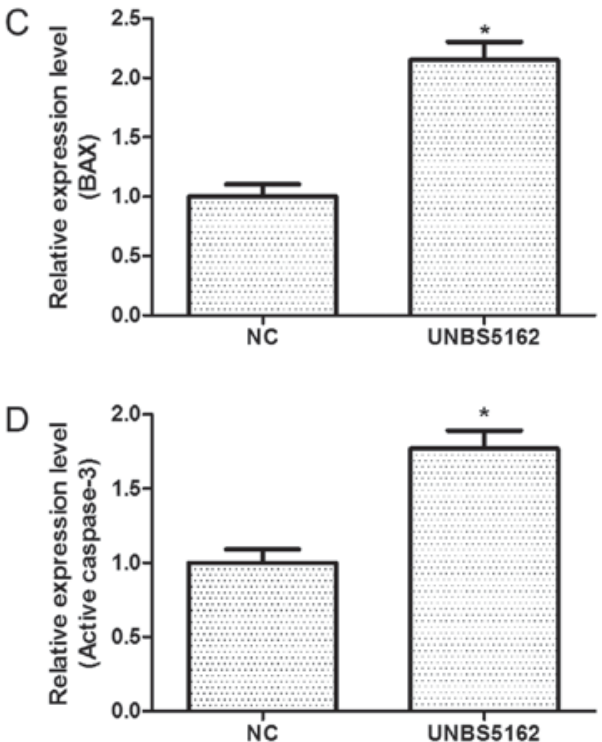

Figure 3. The effect of UNBS5162 on MDA-MB-231 cell apoptosis detected using western blot. The experimental group was treated with UNBS5162 and the negative control group (NC) was treated with DMSO. (A) Western blot assay was utilized to determine BCL-2, BAX and active caspase-3 protein expression levels in MDA-MB-231 cells extracts. (B-D) Quantification of the BCL-2 (B), BAX (C) and active caspase-3 (D) was performed and normalized relative to the expression level of GAPDH. Results represent the mean \pm SD for five independent experiments. " $\mathrm{P}<0.05$ vs. the negative control group. Comparison was made by Student's t test.

migration assay, the number of crystal violet positive cells in the UNBS5162 treated group was less than that in the $\mathrm{NC}$ group $(\mathrm{P}<0.05$; Fig. $4 \mathrm{~A}$ and $\mathrm{C})$. These results suggested that UNBS5162 could inhibit the migration and invasion of MDA-MB-231 cells effectively.

UNBS5162 inhibits the activation of PI3K/AKT/mTOR (PAM) pathway. To understand how UNBS5162 affects the viability of MDA-MB-231 cells, western blotting was applied to detect the protein expression of components in the PAM pathway, which plays a critical role in cellular growth and apoptosis (27). The expression of some key proteins in the PAM pathway was detected, including AKT, phosphorylated-AKT (p-AKT), mTOR, phosphorylated-mTOR (p-mTOR), p-P70S6K and P-4EBP1. As shown in Fig. 5, the levels of p-AKT and p-mTOR were decreased significantly compared with the NC group. The phosphorylation levels of P70S6K and 4EBP1, as downstream targets of mTOR, were also decreased after treatment with UNBS5162. According to these experimental data, UNBS5162 might inhibit the viability of MDA-MB-231 cells via the PAM pathway.

\section{Discussion}

This research revealed that UNBS5162 can inhibit TNBC cell proliferation, migration and invasion as well as promote cell apoptosis via blocking the PAM pathway. Therefore, UNBS5162 has a good anti-cancer effect in vitro on TNBC cells.

To date, UNBS5162, as an anti-cancer naphthalimide, has been studied for use for various cancers using basic research and clinical experiments $(23,24)$. Mijatovic et al (23), performed a profound and comprehensive study on the effects and mechanism of UNBS5162 in human prostate cancers and found that UNBS5162 could inhibit the growth of human prostate cancer through different action ways. For example, UNBS5162 was able to act as a pan-antagonist of CXCL chemokine expression to inhibit cancer growth. In addition, Mijatovic et al (23), found that UNBS5162 could inhibit the proliferation of MCF-7 when they used the MTT colorimetric assay to determine the antiproliferative activity of UNBS5162 against nine human cancer cell lines. Because MCF-7 is an ER-positive breast cancer, we thus sought to ascertain whether UNBS5162 can also inhibit the growth of ER-negative breast cancer. TNBC is a type of ER-negative breast cancer, and the MDA-MB-231 cell line is a typical TNBC that possesses stronger drug resistance and has higher rates of recurrence and metastasis. Therefore, we selected the MDA-MB-231 cell to confirm our thinking. In this study, our results showed that UNBS5162 indeed effectively suppressed the proliferation, migration and invasion of MDA-MB-231 cells. Hence, UNBS5162 might a possible therapeutic drug for TNBC treatment in the future. 

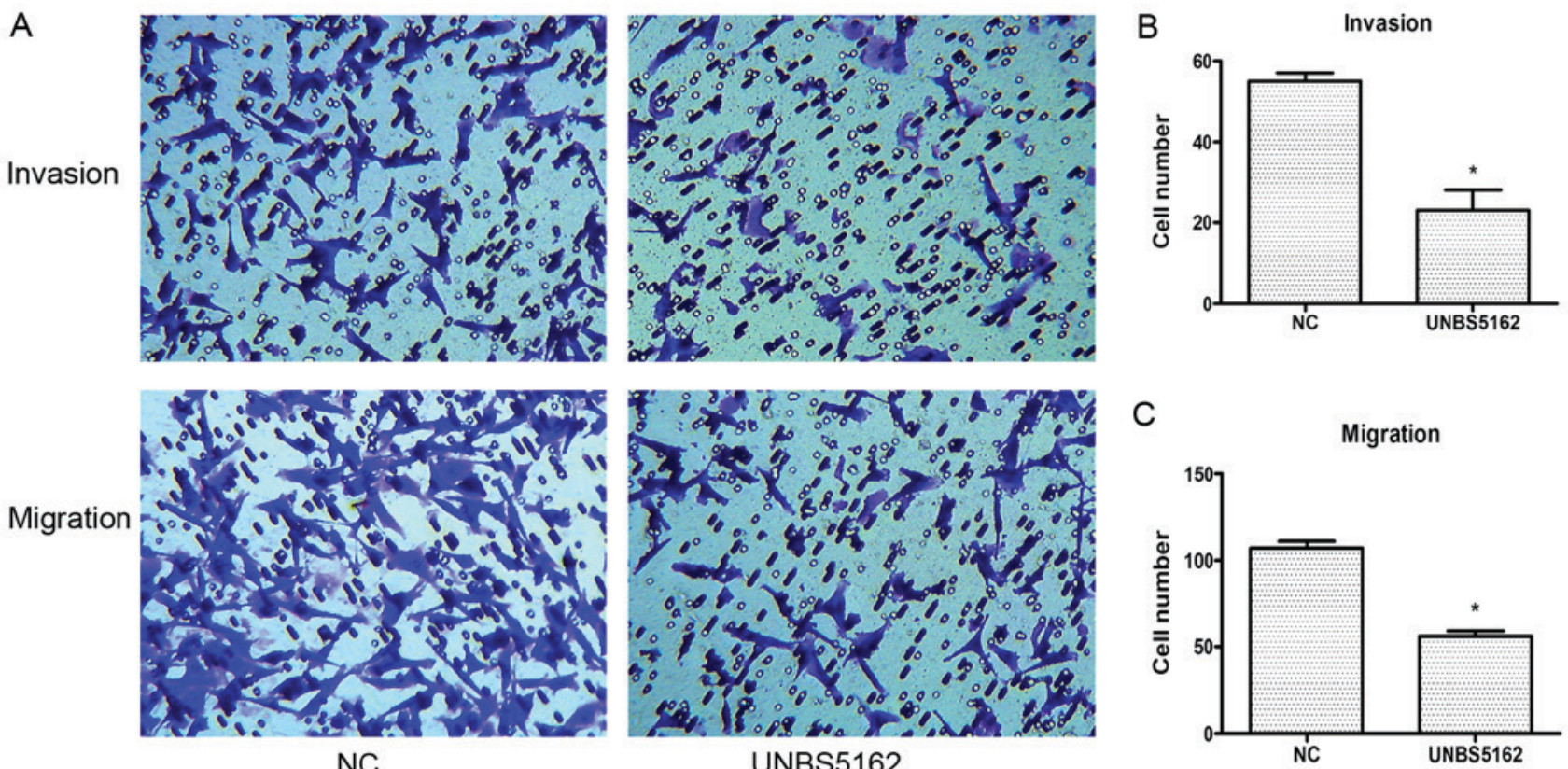

Figure 4. The effect of UNBS5162 on MDA-MB-231 cell migration and invasion. The experimental group was treated with UNBS5162 and the negative control group (NC) was treated with DMSO. After cells were incubated in the matrigel coated and non-matrigel coated chambers of transwells, respectively, MDA-MB-231 cells were fixed in $4 \%$ paraformaldehyde, stained with $0.1 \%$ crystal violet and photographed under microscopic inspection (magnification, $\mathrm{x} 200$ ). Representative images (A) and bar graphs (B and C) depicting the invasion and migration ability of MDA-MB-231 cells treated with UNBS5162. Results represent the mean \pm SD for three independent experiments. " $\mathrm{P}<0.05$ vs. the negative control group. Comparison was made by Student's $t$ test.

A

AKT

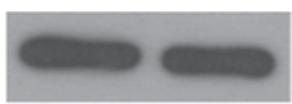

p-AKT

mTOR
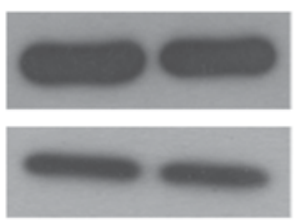

p-mTOR

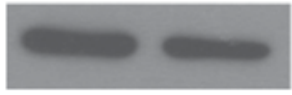

P70S6K

GAPDH
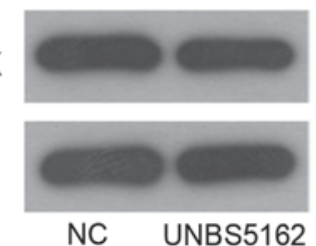
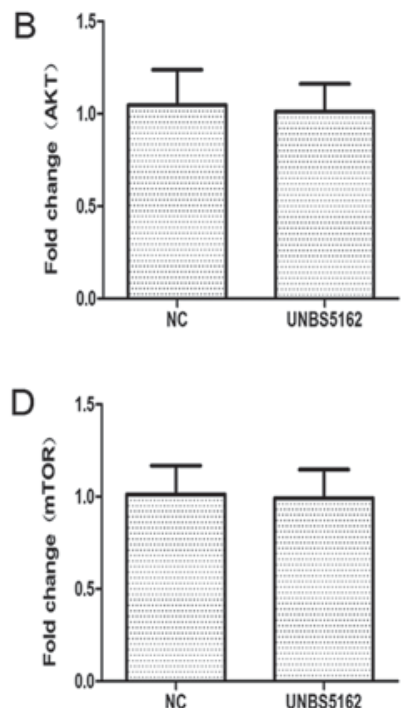
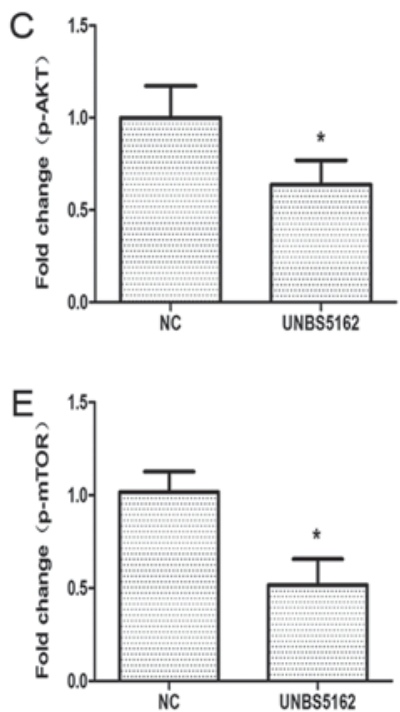

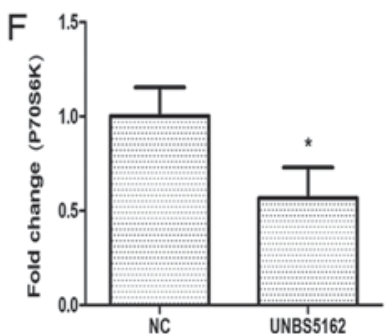

Figure 5. The effect of UNBS5162 on PAM pathway protein expression in MDA-MB-231 cells. The experimental group was treated with UNBS5162 and the negative control group (NC) was treated with DMSO. (A) A western blot assay was utilized to determine AKT, P-AKT, mTOR, p-mTOR, p-P70S6K and P-4EBP1 protein expression levels in MDA-MB-231 cell extracts. Quantification of the p-AKT (B) and p-mTOR (C) bands was performed and normalized relative to the expression level of AKT and mTOR respectively. Quantification of the mTOR (D), P-4EBP1 (E) and p-P70S6K (F) bands was performed and normalized relative to the expression level of GAPDH. The results represent the mean \pm SD for five independent experiments. " $\mathrm{P}<0.05 \mathrm{vs}$. the negative control group. Comparison was made by Student's t test.

Apoptosis is a complex process of programmed cell death that is regulated by a range of cell signals. Apoptosis is initiated and executed through two major pathways, namely, the extrinsic and intrinsic pathways (30). The extrinsic pathway is triggered by extracellular ligands binding to cell surface death recptors. The intrinsic pathway is initiated by a variety of intracellular factors generated when cells are stressed. The BCL-2 family plays a key role in regulating the process of the intrinsic pathway.
BCL-2 and BCL-xL protect the cell against apoptosis, but BAX and BCL-2 homologous antagonist/killer (BAK) induce cellular apoptosis (31). Both pathways have a final common pathway, which involves activation of the effector caspases (caspase-3, caspase-6, and caspase-7) by initiator caspases (32). Therefore, the expression of BCL-2, active caspase-3, BAX becomes one of the celluar apoptosis signs. In our research, the BAX and active caspase-3 levels were increased but BCL-2 level was decreased 
in UNBS5162-treated cells, which demonstrated UNBS5162 accelerated apoptosis of MDA-MB-231 cells.

The PAM pathway regulates many cell functions, mainly associated with cell growth, proliferation and motility regulation (27). Activation of PI3K can phosphorylate and activate AKT, localizing it in the plasma membrane (33). After the activation of AKT, there is a series of downstream effects, such as activating PtdIns-3 ps (34), inhibiting p27 (35), and activating mTOR (35), which can affect transcription of P70S6K and 4EBP1 (35). In addition, the mTOR complexes, mTORC1 and mTORC2, play a critical role in the PAM pathway. The activation of mTORC1 promotes the phosphorylation of P70S6K and 4EBP1 and leads to an increase in protein synthesis and cell growth $(36,37)$. While mTORC1 relays signals following PI3K-AKT activation, mTORC2 contributes to complete AKT activation (37). According to the literatures, the PAM pathway is overactive in TNBC (28), thus allowing cell proliferation and reducing apoptosis. Hence, blocking the PAM pathway by the PI3K inhibitor NVP-BKM120 has been studied for TNBC treatment, and it effectively induced TNBC growth inhibition and apoptosis (15). Ayub et al (38) used PI3K and mTORC inhibitors, namely, NVP-BKM120 and KU0063794, respectively, to regulate the PAM signalling pathway in MDA-MB-231 cells. Their study showed that these inhibitors might suppress cell proliferation and induce apoptosis through the PAM pathway (38). Thus, blocking the PAM pathway is effective in TNBC treatment. In our study, the expression levels of the key PAM pathway proteins that include $\mathrm{p}-\mathrm{AKT}$, p-mTOR, p-P70S6K and P-4EBP1 were obviously decreased after TNBC cells were treated with UNBS5162. Based on the changes of p-AKT, p-P70S6K and P-4EBP1, both mTORC1 and mTORC2 could effectively involve in the roles of UNBS5162 and influence the cell growth. Therefore, UNBS5162 might inhibit TNBC cell proliferation and metastasis and induce apoptosis via inhibiting the PAM pathway. However, one phenomenon cannot be ignored: A negative feedback loop during monotherapy with UNBS5162 might play a role in PAM pathway, which would obviously reduce the effect of UNBS5162. To prevent this phenomenon, combined UNBS5162 with other drugs to cure TNBC is one of our future research directions.

According to the above mentioned work, UNBS5162 as a potential anti-cancer drug could be applied to treat TNBC in the future. Certainly, this is just a preliminary study into the use of UNBS5162 for TNBC treatment. The pharmacodynamics, toxicology and detailed mechanism for the inhibition of UNBS5162 on TNBC remain to be elucidated by animal experiments and clinical tests in the future.

\section{Acknowledgements}

Not applicable.

\section{Funding}

No funding was received.

\section{Availability of data and materials}

All data generated or analyzed during this study are included in this published article.

\section{Authors' contributions}

XY performed the experiments and wrote the manuscript. ML and ZX investigated the relevant literature and revised the manuscript. DC collected and analyzed the experimental data. SS designed the experiments and approved the final version manuscript.

\section{Ethics approval and consent to participate}

Not applicable.

\section{Patient consent for publication}

Not applicable.

\section{Competing interests}

The authors declare that they have no competing interests.

\section{References}

1. Torre LA, Bray F, Siegel RL, Ferlay J, Lortet-Tieulent J and Jemal A: Global cancer statistics, 2012. CA Cancer J Clin 65: 87-108, 2015

2. Torre LA, Siegel RL, Ward EM and Jemal A: Global cancer incidence and mortality rates and trends-an update. Cancer Epidemiol Biomarkers Prev 25: 16-27, 2016.

3. Cancer Genome Atlas Network: Comprehensive molecular portraits of human breast tumours. Nature 490: 61-70, 2012

4. Perou CM, Sørlie T, Eisen MB, van de Rijn M, Jeffrey SS Rees CA, Pollack JR, Ross DT, Johnsen H, Akslen LA, et al: Molecular portraits of human breast tumours. Nature 406: 747-752, 2000.

5. Sørlie T, Perou CM, Tibshirani R, Aas T, Geisler S, Johnsen H, Hastie T, Eisen MB, van de Rijn M, Jeffrey SS, et al: Gene expression patterns of breast carcinomas distinguish tumor subclasses with clinical implications. Proc Natl Acad Sci USA 98: 10869-10874, 2001

6. Sorlie T, Tibshirani R, Parker J, Hastie T, Marron JS, Nobel A, Deng S, Johnsen H, Pesich R, Geisler S, et al: Repeated observation of breast tumor subtypes in independent gene expression data sets. Proc Natl Acad Sci USA 100: 8418-8423, 2003.

7. Foulkes WD, Smith IE and Reis-Filho JS: Triple-negative breast cancer. N Engl J Med 363: 1938-1948, 2010.

8. Loi S, Pommey S, Haibe-Kains B, Beavis PA, Darcy PK, Smyth MJ and Stagg J: CD73 promotes anthracycline resistance and poor prognosis in triple negative breast cancer. Proc Natl Acad Sci USA 110: 11091-11096, 2013.

9. Coates AS, Winer EP, Goldhirsch A, Gelber RD, Gnant M, Piccart-Gebhart M, Thürlimann B and Senn HJ; Panel Members: Tailoring therapies-improving the management of early breast cancer: St gallen international expert consensus on the primary therapy of early breast cancer 2015. Ann Oncol 26: 1533-1546, 2015.

10. Goldhirsch A, Wood WC, Gelber RD, Coates AS, Thürlimann B and Senn HJ; 10th St. Gallen conference: Progress and promise: Highlights of the international expert consensus on the primary therapy of early breast cancer 2007. Ann Oncol 18: 1133-1144, 2007.

11. Banda M, Speyer CL, Semma SN, Osual KO, Kounalakis N, Torres Torres KE, Barnard NJ, Kim HJ, Sloane BF, Miller FR, et al: Metabotropic glutamate receptor-1 contributes to progression in triple negative breast cancer. PLoS One 9: e81126, 2014.

12. Pal SK, Childs BH and Pegram M: Triple negative breast cancer: Unmet medical needs. Breast Cancer Res Treat 125: 627-636, 2011.

13. Lehmann BD and Pietenpol JA: Clinical implications of molecular heterogeneity in triple negative breast cancer. Breast 24 (Suppl 2): S36-S40, 2015.

14. Perou CM: Molecular stratification of triple-negative breast cancers. Oncologist 16 (Suppl 1): S61-S70, 2011. 
15. Juvekar A, Burga LN, Hu H, Lunsford EP, Ibrahim YH, Balmañà J, Rajendran A, Papa A, Spencer K, Lyssiotis CA, et al: Combining a PI3K inhibitor with a PARP inhibitor provides an effective therapy for BRCA1-related breast cancer. Cancer Discov 2: 1048-1063, 2012.

16. Braña MF and Ramos A: Naphthalimides as anti-cancer agents: Synthesis and biological activity. Curr Med Chem Anticancer Agents 1: 237-255, 2001.

17. Costanza ME, Berry D, Henderson IC, Ratain MJ, Wu K, Shapiro C, Duggan D, Kalra J, Berkowitz I and Lyss AP: Amonafide: An active agent in the treatment of previously untreated advanced breast cancer-a cancer and leukemia group B study (CALGB 8642). Clin Cancer Res 1: 699-704, 1995.

18. Scheithauer W, Dittrich C, Kornek G, Haider K, Linkesch W, Gisslinger H and Depisch D: Phase II study of amonafide in advanced breast cancer. Breast Cancer Res Treat 20: 63-67, 1991.

19. Kuhn JG, Burris HA III, Jones SF, Hein DE, Willcutt NT, Greco FA, Thompson DS, Meluch AA, Schwartz RS and Brown DM: Phase I/II dose-escalation trial of amonafide for treatment of advanced solid tumors: Genotyping to optimize dose based on polymorphic metabolism. J Clin Oncol 25: 2503, 2007.

20. Ratain MJ, Mick R, Berezin F, Janisch L, Schilsky RL, Williams SF and Smiddy J: Paradoxical relationship between acetylator phenotype and amonafide toxicity. Clin Pharmacol Ther 50: 573-579, 1991.

21. Ingrassia L, Lefranc F, Kiss R and Mijatovic T: Naphthalimides and azonafides as promising anti-cancer agents. Curr Med Chem 16: 1192-1213, 2009.

22. Lv M and $\mathrm{Xu} \mathrm{H}$ : Overview of naphthalimide analogs as anticancer agents. Curr Med Chem 16: 4797-4813, 2009.

23. Mijatovic T, Mahieu T, Bruyère C, De Nève N, Dewelle J, Simon G, Dehoux MJ, van der Aar E, Haibe-Kains B, Bontempi G, et al: UNBS5162, a novel naphthalimide that decreases CXCL chemokine expression in experimental prostate cancers. Neoplasia 10: 573-586, 2008

24. Mahadevan D, Northfelt DW, Chalasani P, Rensvold D, Kurtin S, Von Hoff DD, Borad MJ and Tibes R: Phase I trial of UNBS5162, a novel naphthalimide in patients with advanced solid tumors or lymphoma. Int J Clin Oncol 18: 934-941, 2013.

25. Balkwill F: Cancer and the chemokine network. Nat Rev Cancer 4: 540-550, 2004.

26. Fernandez EJ and Lolis E: Structure, function, and inhibition of chemokines. Annu Rev Pharmacol Toxicol 42: 469-499, 2002.

27. Liu P, Cheng H, Roberts TM and Zhao JJ: Targeting the phosphoinositide 3-kinase pathway in cancer. Nat Rev Drug Discov 8 627-644, 2009
28. Massihnia D, Galvano A, Fanale D, Perez A, Castiglia M, Incorvaia L, Listì A, Rizzo S, Cicero G, Bazan V, et al: Triple negative breast cancer: shedding light onto the role of pi3k/akt/mtor pathway. Oncotarget 7: 60712-60722, 2016.

29. Blanchard Z, Paul BT, Craft B and Elshamy WM: BRCA1-IRIS inactivation overcomes paclitaxel resistance in triple negative breast cancers. Breast Cancer Res 17: 5, 2015.

30. Krammer PH: CD95's deadly mission in the immune system. Nature 407: 789-795, 2000.

31. Lo AC, Woo TT, Wong RL and Wong D: Apoptosis and other cell death mechanisms after retinal detachment: Implications for photoreceptor rescue. Ophthalmologica 226 (Suppl 1): S10-S17, 2011.

32. Krammer PH, Arnold R and Lavrik IN: Life and death in peripheral T cells. Nat Rev Immunol 7: 532-542, 2007.

33. King D, Yeomanson D and Bryant HE: PI3King the lock: Targeting the PI3K/Akt/mTOR pathway as a novel therapeutic strategy in neuroblastoma. J Pediatr Hematol Oncol 37: 245-251, 2015.

34. Man HY, Wang Q, Lu WY, Ju W, Ahmadian G, Liu L, D'Souza S, Wong TP, Taghibiglou C, Lu J, et al: Activation of PI3-kinase is required for AMPA receptor insertion during LTP of mEPSCs in cultured hippocampal neurons. Neuron 38: 611-624, 2003.

35. Rafalski VA and Brunet A: Energy metabolism in adult neural stem cell fate. Prog Neurobiol 93: 182-203, 2011.

36. Rozengurt E, Soares HP and Sinnet-Smith J: Suppression of feedback loops mediated by $\mathrm{PI} 3 \mathrm{~K} / \mathrm{mTOR}$ induces multiple overactivation of compensatory pathways: An unintended consequence leading to drug resistance. Mol Cancer Ther 13: 2477-2488, 2014.

37. Courtney KD, Corcoran RB and Engelman JA: The PI3K pathway as drug target in human cancer. J Clin Oncol 28: 1075-1083, 2010.

38. Ayub A, Yip WK and Seow HF: Dual treatments targeting IGF-1R, PI3K, mTORC or MEK synergize to inhibit cell growth, induce apoptosis, and arrest cell cycle at G1 phase in MDA-MB-231 cell line. Biomed Pharmacother 75: 40-50, 2015.

This work is licensed under a Creative Commons Attribution-NonCommercial-NoDerivatives 4.0 International (CC BY-NC-ND 4.0) License. 